\title{
Analysis of Creative Drama Education Based on Transverse Ability Training
}

\author{
Ping Xu, Degang $\mathrm{Xu}^{*}$
}

\author{
Zaozhuang University, Zaozhuang, China
}

*Corresponding author. Email: X6136866@126.com

\begin{abstract}
To grow into high-quality preschool teachers, students majoring in preschool education in colleges and universities should have cross-disciplinary thinking ability, integrate knowledge and skills in different fields, and have excellent professional ability, profound professional quality and integrated innovation ability. Transversal ability is a general ability that runs through different disciplines and fields, and it is also a comprehensive accomplishment, which accords with the concept of all-round development of modern society. The exploration and practice of creative drama education should be carried out from the perspective of cross-cutting ability training, so as to break the isolation of various disciplines, carry out interdisciplinary cooperation and exchange, integrate related disciplines, and cooperate with teachers of different disciplines to build a three-dimensional and open teaching system. Creative drama education based on cross-cutting ability can stimulate students' enthusiasm and creativity, cultivate students' practical ability, teamwork spirit and aesthetic ability, develop students' multi-thinking ability and innovative ability, promote the formation of their mental health and sound personality, enhance their comprehensive quality, help them form a scientific and open view of modern children's education, and make them grow into qualified preschool teachers.
\end{abstract}

Keywords: Cross-cutting ability of preschool education major, Creativity, Comprehensive quality of drama education.

\section{INTRODUCTION}

Preschool education is the beginning of lifelong learning, which lays a good quality foundation for children's healthy growth and lifelong development. In this starting stage of life, high-quality preschool teachers play a key role in leading children's education. Since the new period, China has paid more and more attention to the development of preschool education, especially the construction of preschool teachers. In 2010, the State Council's "Several Opinions on the Current Development of Preschool Education" pointed out: "Accelerate the construction of a preschool teacher team with high morality, love for children, excellent business and reasonable structure"; In 2014, the Ministry of Education promulgated the "Opinions on Implementing the Excellent Teacher Training Program", clearly pointing out that it is necessary to "train a group of outstanding kindergarten teachers who love preschool education, have comprehensive quality and outstanding teaching ability"; In 2018, the Central Committee of the
Communist Party of China and the State Council issued "Several Opinions on Deepening Reform and Standardized Development of Preschool Education" on this basis, proposing to vigorously strengthen the construction of kindergarten teachers, to "innovate the training mode, optimize the training curriculum system, highlight the integration of education and protection and improve the professional level of training". These policies and regulations put forward comprehensive, scientific and rigorous requirements for preschool teachers' moral quality and ability accomplishment.

As preschool teachers in the future, students majoring in preschool education in colleges and universities should be engaged in the whole subject teaching in the future, so as to achieve the integration of teaching and protection, which requires them to have the cross-disciplinary ability, organically integrate knowledge and skills in different fields, and have excellent professional ability, profound professional quality and integrated innovation ability. The exploration and practice of creative drama education from the perspective of cross-ability training is helpful to 
stimulate students' thinking integration ability, cultivate students' practical ability, team consciousness and cooperation spirit, develop students' creative ability, promote their mental health, enhance their aesthetic ability, help them form a scientific and open view of modern children's education, and make them grow into qualified preschool teachers.

\section{CONNOTATION OF TRANSVERSAL ABILITY}

Transversal competences was first proposed by Finland. In December 2014, the National Education Commission of Finland published the National Core Curriculum of Basic Education for Grades 1-9, and also published the curriculum reform program for preschool education and senior high school education at the same time. The new curriculum reform aims at cultivating talents to adapt to the ever-changing future society, and defines seven "traversing abilities" that students need, emphasizing and promoting the infiltration of "traversing abilities" into traditional subject teaching. After two years of phenomenal experimental teaching, the new curriculum reform was formally implemented in August 2016, which requires strengthening the cultivation of cross-cutting ability in all subjects. In the concrete implementation, local education authorities and schools are encouraged to achieve the goal of cultivating students' cross-cutting ability in their own innovative ways. This progressive and perfect teaching reform in Finland is of great significance for promoting students' all-round development, which has attracted the attention and study of all countries in the world.

The seven cross-cutting abilities required by Finland's educational reform mainly include the following contents: thinking and learning ability, cultural accomplishment, communication and self-expression, daily life skills and self-protection ability, multi-reading ability, information technology ability, working and living ability and entrepreneurial spirit, and the ability to participate in, influence and build a sustainable future. These seven cross-cutting abilities are not independent and self-contained, but complement each other and integrate with each other, which is not only reflected in the organizational integration of specific teaching objectives at the implementation level, but also reflected in the comprehensive general ability of interdisciplinary and interdisciplinary and the value orientation of devoting to cultivating all-round talents, which also points to the improvement of students' internal learning ability and the adaptation of external social life. [1] It is the necessary ability and accomplishment for students to adapt to the increasingly competitive pluralistic society.

It can be seen that traversing ability refers to the general ability that runs through different disciplines and fields. It is not equal to general knowledge or ability, it is not an isolated existence, but belongs to the category of comprehensive quality, and it is a comprehensive expression of facing specific situations including values, emotions, attitudes and wishes. [2] Compared with traditional disciplinary competence, cross-disciplinary competence emphasizes the integration and penetration of multiple abilities and the integration and transfer of interdisciplinary knowledge. This ability transcends the boundaries of disciplines, breaks down the original barriers of various disciplines, and organically and flexibly integrates knowledge and skills in different fields. Emphasizing the awareness of solving specific work problems across professional fields, we can use our own professional knowledge to solve specific problems of other disciplines, or use other professional knowledge to solve our own professional problems, or integrate and integrate the relevant knowledge of various majors, and use them flexibly to think and analyze problems from multiple angles, levels and fields, so that students can gradually grow up and calmly face various needs of personal development, study work and participation in public affairs, and finally realize the all-round development of people.

\section{THE CONNOTATION OF CREATIVE DRAMA EDUCATION}

Creative drama education originated in America. In 1930, American drama educator Winifred Wards published his book Creative Dramatic, which marked the establishment of the position of creative drama in children's drama education. In 1977, the American Theater and Education Alliance (AATE) gave a formal definition of "creative drama": it is an impromptu, non-performing, process-centered drama form, in which participants imagine, play and reflect on human real or imagined experiences under the guidance of their guides. In 1983, Davis further pointed out that creative drama is a "guide", which guides "participants" to explore, experience, develop and express by using their pretending game instinct, communicate each other's thoughts, concepts and feelings through the interactive way of drama, and imagine and experience human life experience together to build a consensus and cooperation relationship. [3]

Since 1960s, creative drama has gradually entered the classrooms of primary and secondary schools in Europe and America, which plays an important role in cultivating and developing students' abilities. In the early 1990s, the concept of creative drama education spread to Taiwan. With the vigorous promotion of scholars such as Lin Meijun, creative drama education has become a compulsory subject in primary and secondary schools in Taiwan since 2001. Professor Lin Meijun devoted herself to the theoretical research and practical exploration of creative drama education for many years. She summed up the connotation of creative drama: "Creative drama is an impromptu and spontaneous classroom activity. Its 
development focuses on the process of participants' experience reconstruction and the expression of their actions and spoken "spontaneity". Under the natural and open classroom atmosphere, a leader uses questioning skills, telling stories or props to arouse motivation, and encourages participants to use' pretentious' game instinct to imagine and express with their own body and voice through various drama activities such as body rhythm, impromptu mime, facial sensation and situational dialogue. In the group interaction, each participant must face, explore and solve the problems and situations faced by the story characters or himself, so as to experience life, understand the relationship between people and self, build self-confidence, and then become a free creator, problem solver, experience integrator and social participant." (<creative drama theory and practice>)

To sum up, we can know that creative drama education is an impromptu and spontaneous performance activity, which mainly includes rhythmic activities, mime, role playing, imitation action, story telling, puppet play, drama playing and other forms. It gets rid of the shackles of traditional stage performances, transcends the original category of literature and art, and can flexibly choose the form, content, time, venue and personnel for simple and appropriate performance. It emphasizes the performance process rather than the result, not for the audience's appreciation, nor for training qualified actors, but for everyone's active participation, and encourages participants to experience various emotions in the performance, so as to achieve self-growth. According to the characteristics of disciplines and curriculum content, cross-disciplinary and cross-curriculum integration, and the use of open and diverse performance forms to reproduce different teaching contents, not only are vivid and concrete, but also improve students' ability of unity and cooperation and practical innovation, and gradually help students to form cross-thinking ability and improve their comprehensive quality.

The main implementation environments of creative drama education activities are kindergartens and primary schools. It pays attention to children's experience and growth in the process of drama performance, and focuses on solving drama conflicts. Under the guidance and guidance of teachers, the rules of the game are clear and the implementation forms are flexible and diverse, so that children can fully display and express themselves in a free environment. It has the characteristics of process, improvisation, pluralism, comprehensiveness, situation, group, integrity, repeatability, performance and so on. It plays an important role in the healthy development of children's body and mind and ability training, so it has been paid more and more attention and promoted in recent years.

However, creative drama education is not only beneficial to children's all-round development, but also of great significance and role for today's preschool students and future preschool teachers to cultivate and enhance their various abilities and become the promoters and leaders of creative drama education in kindergartens. Creative drama education is not aimed at learning drama knowledge and performance skills, but focuses on training students to understand society, think about life, cultivate their abilities and enhance their own quality through drama performance, and attaches importance to the cultivation and realization of participants' communication, expression, emotion, imagination, creativity and team consciousness. [4] Therefore, the integration of creative drama education into the pre-school students' training courses in colleges and universities is not only an education of knowledge and skills, but also an ideal emotional education and aesthetic education, which is conducive to cultivating and improving students' practical ability, teamwork ability, creative ability, imagination ability and aesthetic ability, and promoting the formation of mental health and good personality.

\section{CREATIVE DRAMA EDUCATION BASED ON CROSS-CUTTING ABILITY TRAINING}

Transversal ability is the general ability and comprehensive quality that runs through different disciplines and fields, which accords with the idea of all-round development of people in modern society. At present, all disciplines and courses of preschool education are still dominated by traditional teaching methods. Teachers of all disciplines lack organic communication and integration, and have not yet formed a complete cross-cutting ability to cross and integrate all disciplines. Therefore, students also lack this cross-cutting awareness and cross-cutting ability. Therefore, it is one of the main goals of preschool education major in colleges and universities to cultivate students' cross-cutting ability, comprehensively improve students' comprehensive quality, help students become applied and innovative talents, and provide a strong teacher guarantee for cultivating children's creativity and imagination.

Drama is a comprehensive art integrating literature, art, music, dance, etc. It is called "the seventh art", which spans many disciplines, has far-reaching cultural significance and aesthetic value, and can promote people's all-round development and cultivate sound personality. Creative drama education not only has the goal of cultivating all-round education, but also has the practical application of developing the ability of drama art. At the same time, it has the characteristics of wide coverage, high participation rate, flexible and diverse forms, rich and colorful contents and full of creativity, etc. It can organically integrate many disciplines, and is especially suitable for school teaching activities. Creative drama education based on cross-disciplinary ability 
training will change the teaching situation of relatively isolated and lack of connection among disciplines. Through cross-disciplinary and cross-disciplinary connection, we can optimize and integrate related courses, realize cross-disciplinary and cross-professional education integration and innovation, build an open and three-dimensional pre-school professional education model in colleges and universities, gradually cultivate students' cross-disciplinary thinking ability and cross-disciplinary research ability, and guide and think students in understanding society, feeling life, cultivating ability and improving literacy, so as to promote them to form a three-dimensional circular network thinking mode.

Students majoring in preschool education will become preschool teachers in the future, while preschool teachers' professional characteristics are children's enlightenment and education protection activities regardless of disciplines. In kindergarten teaching activities, which mainly focus on artistic activities, more attention is paid to preschool teachers' professional traversing ability. [5] Pre-school teachers with cross-cutting ability not only have all-discipline literacy, but also systematic scientific training will make them consciously possess and use cross-cutting ability to think and analyze problems, which will help them to have integrated innovation ability and three-dimensional thinking ability, and be able to interpret, analyze and integrate and solve related problems from multiple angles, levels and fields. In addition, it helps them to form a scientific, inclusive and open view of children's education, and promotes the healthy development of children's body and mind. A preschool teacher with cross-cutting ability is bound to be forward-looking, with various forms, flexible thinking, innovation and imagination when guiding and educating children, which can better cultivate children's innovative ability and aesthetic ability, and lay the foundation for children's sound personality development.

\section{IMPLEMENTATION OF CREATIVE DRAMA EDUCATION ACTIVITIES}

Creative drama education based on cross-cutting ability training is to break the isolation of various disciplines, carry out cross-disciplinary cooperation and exchange, integrate related disciplines organically, and cooperate, cross-border complement and integrate teachers of different subjects to jointly build a three-dimensional and open teaching system. Under the guidance of teachers, students unite and cooperate, explore independently, apply their knowledge flexibly, and consciously absorb relevant unknown knowledge. By observing and thinking, interpreting and analyzing, exchanging and cooperating, students integrate knowledge points of various disciplines, and subtly form certain general ability, overall planning and integration ability and integrated innovation ability. [6] Therefore, we can learn from the phenomenon teaching in Finland's curriculum reform, that is, "selecting specific real phenomena or topics from real life according to students' needs, and integrating the knowledge of related disciplines to carry out teaching, the essence of which is to set up interdisciplinary learning modules and carry out thematic teaching. According to the arrangement of the talent training plan, a new interdisciplinary theme is selected every year or every semester, and cross-learning research between courses is concentrated. Teachers from different disciplines form teaching experimental groups, establish interdisciplinary learning modules, form a community of interdisciplinary teaching and learning, carry out the overall design of teaching activities on corresponding topics, and organize teaching for some topics that students are interested in. (Han Baojiang. $<$ Phenomenal Teaching of Basic Education in Finland $(2)>)$

For example, around the theme of "childhood memory", creative drama education is the main form, and interdisciplinary learning and communication are carried out through integration and blending. You can select content, organize materials, and make it into children's songs, children's stories, children's picture books, children's scripts and other forms. On this basis, continue to innovate, and can be adapted into children's drama (bilingual), children's song and dance drama, sitcom, puppet show, pantomime, shadow play, story performance, impromptu performance, games, rhythmic exercises, interviews and other forms, and choose appropriate links in the course study for practical display; Education, language, literature, art, music, dance, sports, computer and other disciplines must be involved in the process of performance creation, showing the cooperation of many courses such as Chinese, children's literature, children's drama creation and performance, teachers' oral English, kindergarten education activity design, children's song playing, children's dance creation, manual work and children's physical intelligence games. Training students' skills in writing, composing, oral expression, drama performance, painting, playing and singing, dancing, hand-made, game design, multimedia production, action design, etc., cultivating students' abilities of independent inquiry, teamwork, aesthetic imagination, multi-thinking, overall planning, integrated development, innovation and creation, etc., so that they have cross-learning ability, cross-research ability and cross-thinking ability, and further enhance students' ability. Example below: 


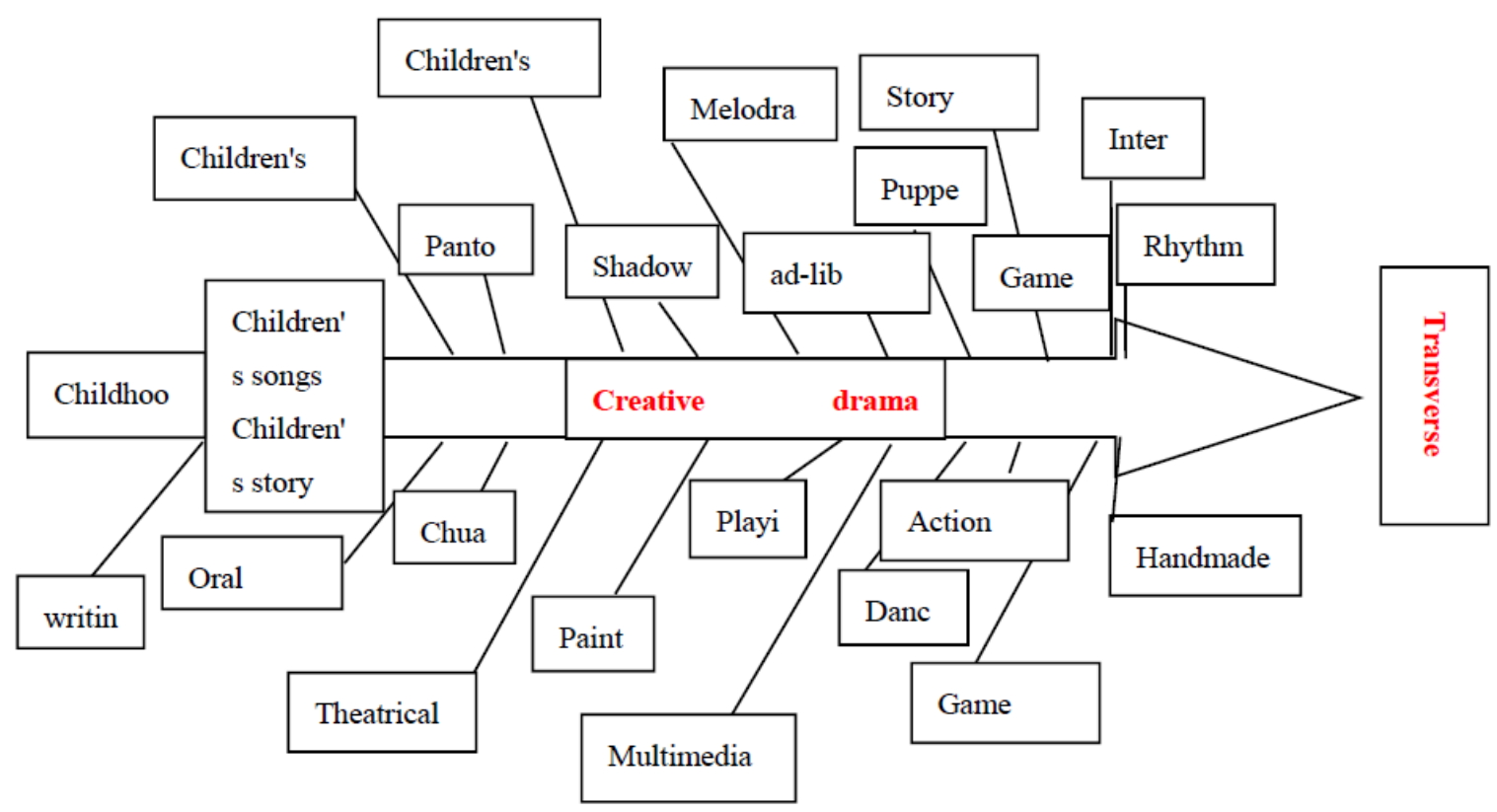

Figure 1 Schematic representation of creative theatrical activity

Teachers and students discuss together, prepare suitable creative themes, and students arrange tasks according to the team and work together. Combined with the characteristics of various disciplines and courses, some forms of creative drama are selected, detailed plans are made and put into practice. Such as constructing space, singing and dancing arrangement, game gymnastics design, multimedia auxiliary means preparation, role interaction and so on. Through design preparation, practical operation, observation and reflection, summarization and evaluation, a series of experience activities in "learning by doing" have really been realized. This kind of activity is open, uncertain and full of challenges, which allows students to display their creativity according to their own specialties, around the chosen theme, using suitable materials, forms and methods, thus greatly inspiring students' enthusiasm for participation and stimulating their innovative ability.

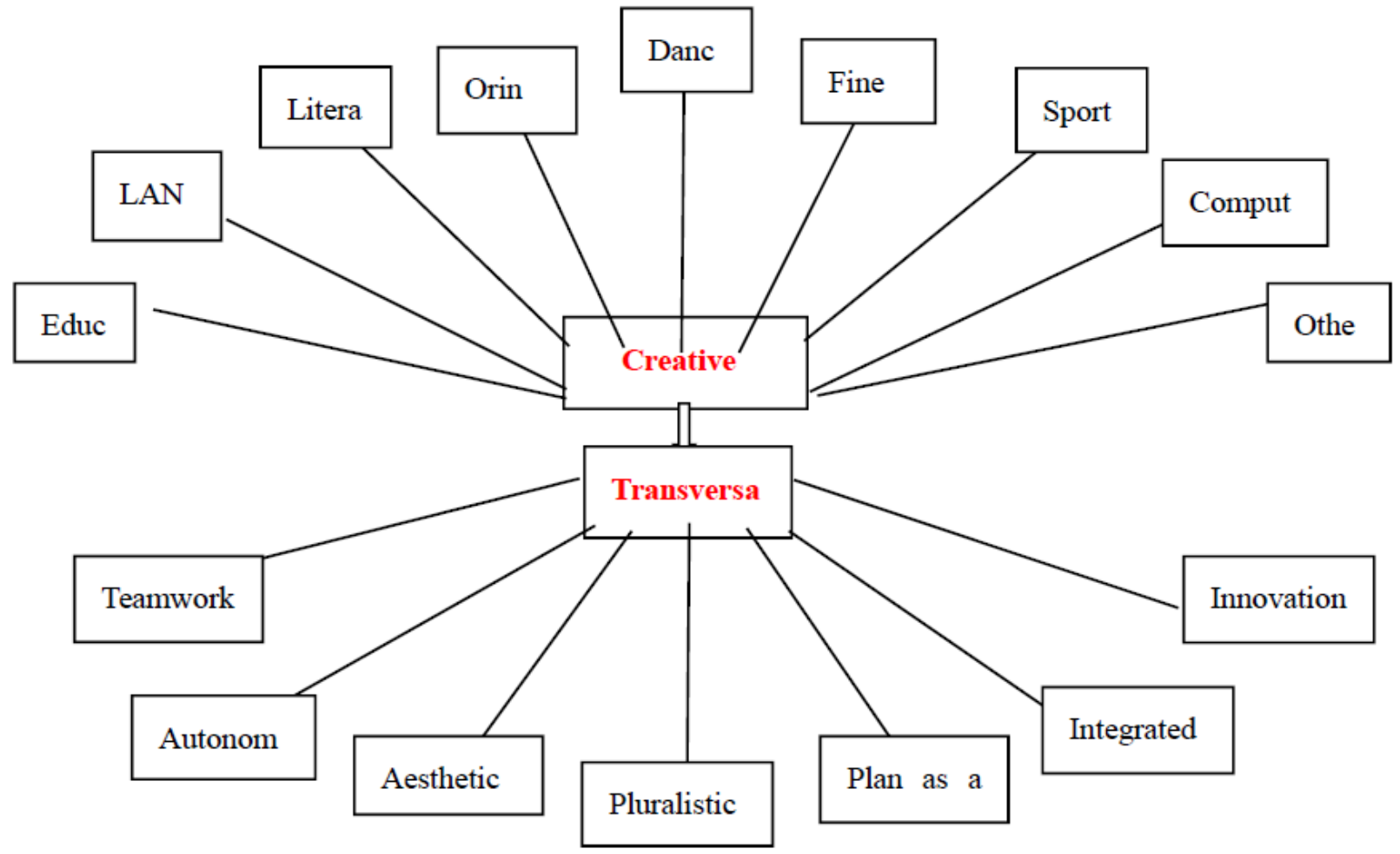

Figure 2 Schematic illustration of subject integration and capacity development 
Taking the creation of drama activities as the basic point, we should break the inherent barriers of various disciplines, flexibly blend various disciplines and organize and integrate various courses, organically integrate fragmented knowledge, carry out research in multi-disciplines, multi-angles, multi-dimensions, multi-levels andmulti-fields, and flexibly advance in an open, divergent, combined and integrated way, thus presenting a three-dimensional open professional education system systematically and completely. It can not only cultivate students' multiple thinking and various cross-cutting abilities, and make students form systematic, omni-directional and deep cognition and thinking on problems, but also make them have a cross-cutting vision, consciously use cross-cutting thinking methods to analyze and solve problems, and comprehensively improve comprehensive ability and core literacy, which will play an important role in future study, work and adaptation to society.

\section{CONCLUSION}

In 2016, China officially established the "Sino-Finnish Joint Learning and Innovation Institute" to study Finland's education reform and cross-cutting ability training, and issued the overall framework of "Chinese Students' Development Core Literacy" in that year to lead the curriculum reform and education mode reform. On the whole, the elements and connotations of trans-competence put forward by Finland and the six core indicators and 18 key points put forward by China have the wonderful work of the same industry, which take into account the organic integration of knowledge, skills, emotions, attitudes and values, and pay attention to the cultivation and promotion of comprehensive literacy. [7] Therefore, in-depth analysis and exploration of creative drama education based on cross-cutting ability training is in response to the requirements of curriculum reform in the new era in China, in line with the concept of pluralistic and intelligent development in modern society, and has far-reaching significance for improving the training mode of preschool students in colleges and universities, promoting the construction of core literacy and promoting people's all-round and healthy development.

\section{ACKNOWLEDGMENTS}

This paper is the stage achievement of the national research project "Wushu Culture and the Construction of the Common spiritual Home of the Chinese nation "(subject No.:18 CYMJ38) of the National people's Commission.

\section{REFERENCES}

[1] Enlightenment of the cultivation of cross-cutting ability in Finland's national core curriculum reform to China $[\mathrm{J}]$. Feng Huimin, Guo Hongrui. Foreign primary and secondary education .2017. (10)

[2] Where is the "new" in Finland's new curriculum reform $[\mathrm{J}]$. yan wang, Cai Yuzhao. People's Education .2016. (24)

[3] Research on Teacher Guidance Based on Creative Drama — Taking a kindergarten in Harbin as an example [J]. Feng Junzhu. Master thesis .2016. (06)

[4] Preliminary Exploration of Creative Drama Education in Higher Vocational Colleges [J]. Suo Lizhen. Chinese Staff Education .2014. (08)

[5] Research on Art Education Based on Transversal Ability _ Taking Preschool Education as an Example [J]. Shao Zhuchun. Education and Teaching Research .2017 (12)

[6] Phenomenal Teaching of Basic Education in Finland (2) [J]. Han Baojiang. Reference of Basic Education .2019. (07)

[7] Path Analysis of Core Literacy Landing Experience and Enlightenment of Finland [J]. Yin Jianhua, Wei Hongtao. Basic Education Curriculum .2019 (09) 